\title{
EL PORVENIR, SAN MIGUEL CHIMALAPA, OAXACA: UNA FORMA HÍBRIDA DE ORGANIZACIÓN EJIDAL*
}

\author{
EL PORVENIR, SAN MIGUEL CHIMALAPA, OAXACA: A HYBRID FORM \\ OF COMMUNAL LAND ORGANIZATION
}

\author{
Melva López Nazario**
}

\begin{abstract}
En este artículo muestro cómo la organización ejidal fue encarnada de manera específica en una zona oaxaqueña. El ejido El Porvenir se formó en el auge del cardenismo y en los años cincuenta adquirió un tipo de organización que llamaré comunal, es decir, un híbrido en el que la estructura formal del ejido tomó características de la organización que se piensa propia de población indígena. La organización ejidal y la ampliación de las funciones de la asamblea al ámbito civil y comunitario ha permitido forjar una comunalidad cuya historia se ha transmitido de generación en generación. En apariencia han mantenido las formas organizativas surgidas de las políticas gubernamentales, pero lo han logrado gracias a la formulación de una comunidad ejidal que le da sentido a la vida en colectivo, que rebasa las áreas de dominio productivo e incide en el control de recursos naturales y en problemas de gobernabilidad más amplios.
\end{abstract}

Palabras claves: ejido, comunidad, comunalidad, organización política.

In this article I show how the ejido organization was specifically embodied in a Oaxacan area. The ejido El Porvenir was formed in the period of president Cardenas (1934-1940) and in fifties acquired a type of organization that I define as community, a hybrid in which the formal structure of the ejido took characteristics of the organization that is supposed specific of indigenous population. The ejido organization and expansion of the functions of the Assembly to civil and community areas, allowed the forge of a commonality whose story has been passed down from generation to generación. In appearance remained the organizational forms that emerged from government policy, but they have achieved a new way through to the formulation of an ejido community that gives meaning to life group, which exceeds the areas of productive domain and affects the control of natural resources and broader governance issues.

Key words: Ejido, community, Communality, Political Organization.

\section{Introducción}

En este trabajo muestro un ejemplo de cómo la organización ejidal fue encarnada de manera específica en una zona oaxaqueña. El Porvenir, si bien es un ejido integrado por población mestiza ${ }^{1}$ y formado en el auge del cardenismo, en los años cincuenta adquirió un tipo de organización que llamaré comunal, es decir, un híbrido en el que la estructura formal del ejido tomó características de la organización que se piensa propia de población indígena con tierras comunales y sistema de cargos.

Este caso es importante porque rompe esquemas simplistas que identifican a los territorios ejidales como mestizos e independientes de las características de la organización de los pueblos indios. Pero, en la realidad, hay ejidos integrados por indígenas que no conservan formas comunales, como Misión de Chichimecas, Guanajuato, por ejemplo (Cfr. Escutia, 2010), al lado de ejidos integrados por mestizos que adquirieron la comunalidad como estrategia para lograr cierta gobernabilidad, como es el caso de El Porvenir.

Lo que en mi opinión hace la diferencia es, por un lado, el contexto de ambos casos: el primero en una región donde predominaron las haciendas y los esquemas de corte ranchero, y el segundo se ubica en un contexto indígena donde la asamblea ha sido el recurso organizativo básico para la toma de decisiones. En efecto, El Porvenir es el único ejido en el municipio de San Miguel Chimalapa que, a su vez, comprende las tierras comunales reconocidas oficialmente a los zoques en los años sesenta. Por ello, sería erróneo afirmar categórica y unilateralmente que el sistema ejidal fue absorbido por una matriz regional indígena, ya que esta absorción, en

\footnotetext{
* Este trabajo es una reflexión que retoma los materiales de la investigación realizada en conjunto con Jorge Antonio Acosta Calderón, cuyos resultados fueron presentados en 2010 en la ENAH como tesis de Licenciatura en Antropología Social, con el nombre de "Cambio social y poder: la construcción del ejido El Porvenir, San Miguel Chimalapa, Oaxaca, 1936-2008".

** Escuela Nacional de Antropología e Historia, México. Correo Electrónico: mmmelva@ yahoo.com.mx
} 
mi opinión, respondió a necesidades concretas de los ejidatarios en una etapa básica de su historia. En esa línea de ideas es que me propongo hacer un recorrido histórico del ejido estudiado para ilustrar por qué se adoptó esta forma de organización híbrida y por qué sigue vigente.

La importancia de investigar este tipo de casos radica en evidenciaar la complejidad del campo mexicano: que la organización ejidal, con las características que adquirió en El Porvenir, rebasa las áreas de dominio productivo e incide en el control de recursos naturales y en problemas de gobernabilidad más amplios.

\section{El ejido El Porvenir y su contexto}

El Porvenir está ubicado en la región del Istmo Oaxaqueño (ver Mapa 1) y es el único poblado del municipio de San Miguel Chimalapa ${ }^{2}$ que está conformado como ejido. Fue dotado el 28 de agosto de 1940 con una superficie de 2.912 ha que fueron tomadas de la exhacienda de Ingenio Santo Domingo, para el beneficio de 174 familias campesinas (DOF, 21/10/1940). El resto de los asentamientos y de la superficie municipal corresponden a las 134 mil ha que les fueron restituidas a los zoques de San Miguel en forma de Bienes Comunales (DOF, 16/03/1967).

Por su carácter de ejido y agencia municipal, en El Porvenir hay dos tipos de autoridades: la civil y la agraria. El agente municipal es la autoridad civil, mientras que en el ámbito agrario están la Asamblea General, el Comisariado Ejidal y el Consejo de Vigilancia. Su organización básica emanó de las disposiciones reglamentarias oficiales, sin embargo, mediante su historia la asamblea se ha vuelto fundamental -lo que señalo como un elemento de la comunalidad-. Las funciones de la asamblea se han ampliado y actualmente es el espacio donde se discuten los asuntos públicos internos, como el control y acceso a los recursos colectivos, la agenda de trabajo para el mantenimiento de los servicios, la asignación y/o venta de los lotes, la elección de autoridades, la presentación de los programas gubernamentales y la organización de la fiesta agraria.

El poblado está ubicado aproximadamente a 35 km de la intersección de la carretera Panamericana con la Transístmica, y puede ser considerado puerta a los Chimalapas ${ }^{3}$, ya que es el primer asentamiento

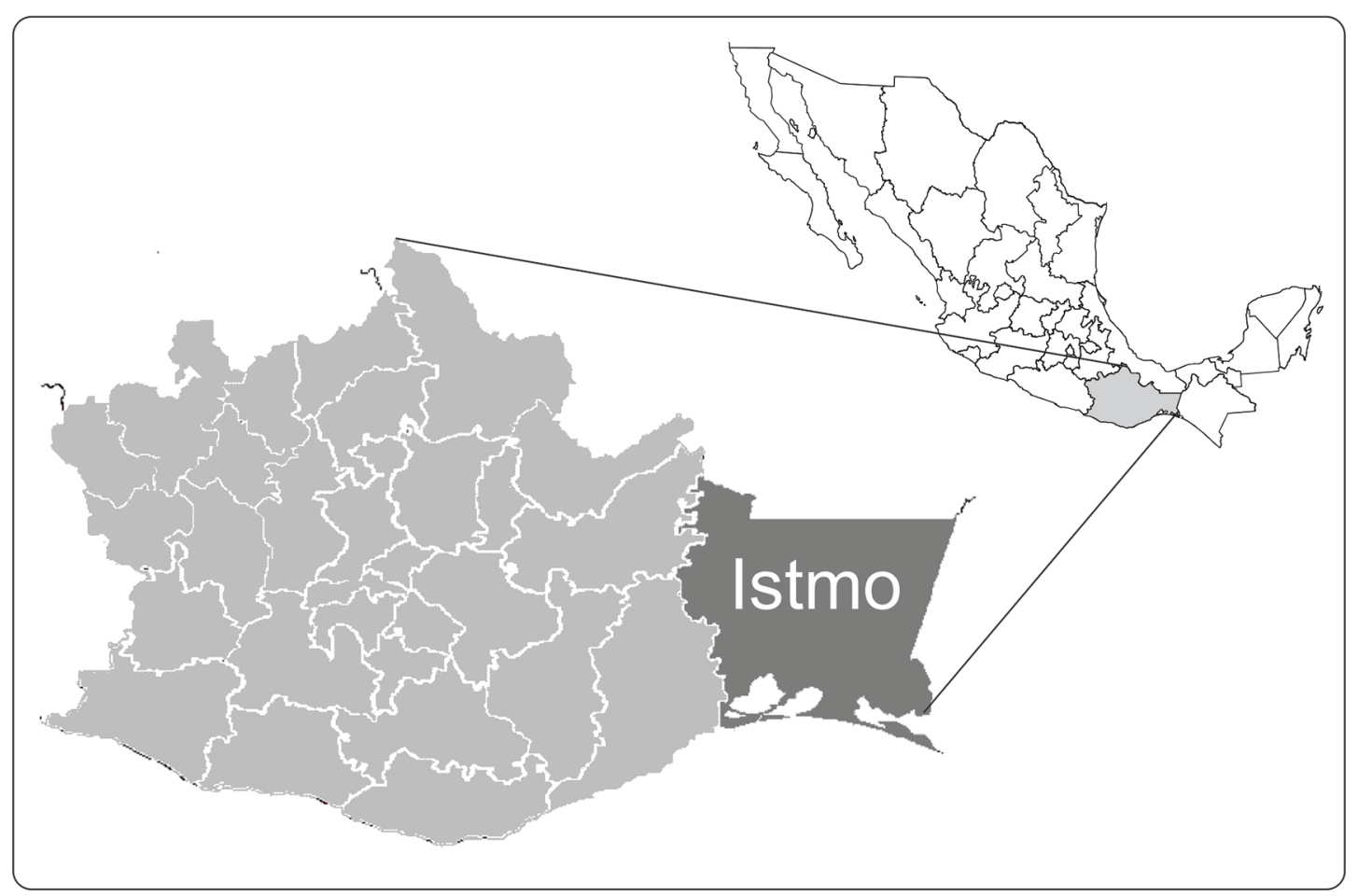

Mapa 1. Región del Istmo, Oaxaca, México.

Fuente: Elaboración propia, basada en el Instituto Nacional de Estadísticas, Geografía e Informática, Carta Topográfica Salina Cruz E15-10, D15-1, México, 2000. 
del municipio en el acceso hacia la cabecera (ver Mapa 2). La población municipal es heterogénea, por la presencia de los grupos étnicos zoque y zapoteco - principalmente-, y una minoría de mestizos. De acuerdo con los resultados del Censo de 2010, el número de habitantes en El Porvenir es de 668, lo que representa alrededor del 10,1\% de los 6.608 habitantes que radican en las 31 localidades del municipio (INEGI, 2010). Como veremos más adelante, los porvenireños actualmente son una población mestiza, integrada por familias zapoteco-zoques, es decir, es un tipo de mestizaje interindígena.

Según la CONEVAL (2005), San Miguel Chimalapa en conjunto presenta rezago social alto, en lo que se refiere a la insuficiencia de planteles escolares, de servicios de salud, servicios básicos -agua, luz y drenaje-, de calidad y espacios en la vivienda, y activos en el hogar. En contraste,
El Porvenir es considerado con rezago social bajo, porque tiene una escuela primaria, una telesecundaria y un Centro de Educación Preescolar Indígena, además cuentan con energía eléctrica y agua potable, así como una Unidad Médica Rural (Cfr. López, 2010). La diferencia es notable e implica por un lado que el proceso de urbanización se ha desarrollado por las facilidades en el acceso al ejido y la organización interna que ha impulsado y gestionado la instalación y mantenimiento de los servicios.

Contrapuesto a la situación de rezago social, los chimas $^{4}$ poseen importantes recursos forestales, hidrológicos y una gran diversidad biológica en su amplia extensión territorial. Actualmente, la selva zoque es considerada como una de las ecorregiones biológicamente prioritarias en el planeta según el Fondo Mundial para la Naturaleza World Wildlife Fund (Galindo, 2009: 445), y es un foco de interés

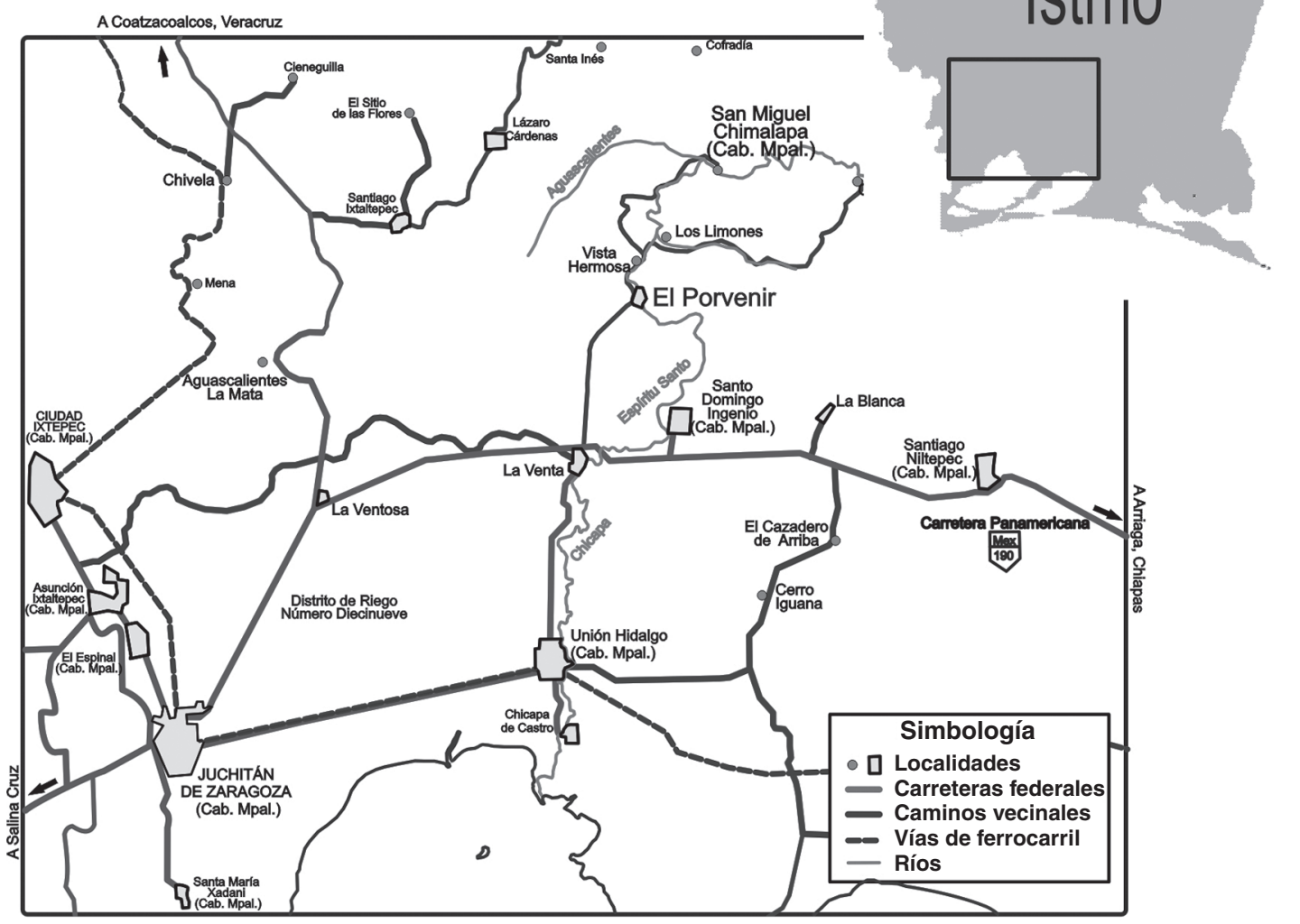

Mapa 2. El Porvenir, región del Istmo, Oaxaca.

Fuente: Elaboración propia, basada en el Instituto Nacional de Estadísticas, Geografía e Informática, Carta Topográfica Salina Cruz E15-10, D15-1, México, 2000. 
para los capitales biotecnológicos que buscan extraer recursos comercialmente valiosos para la genética y la bioquímica (Delgado, 2003); además, múltiples instancias gubernamentales y grupos empresariales ejercen presión en la región del istmo con el desarrollo de proyectos "ecologistas" -como el corredor Eolo eléctrico-, a partir de ello se ha generado un clima de violencia por el despojo de grandes extensiones de territorios de los indígenas.

A nivel nacional, la propiedad social contiene el $80 \%$ de los bosques y selvas y el $74 \%$ de la biodiversidad (SEDATU, 2012), de lo que deriva la importancia de estudiar la organización interna tanto de comunidades agrarias ejidales y de bienes comunales, ya que ahí se encuentran claves para la toma de decisiones en los asuntos públicos que corresponden a más de la mitad del territorio nacional.

A pesar de que no se escapa de los efectos de la contaminación ambiental, la riqueza hidrológica del municipio sigue siendo fundamental para las poblaciones de Santo Domingo Ingenio, La Venta, Unión Hidalgo y Chicapa de Castro, ya que el caudal del río Espíritu Santo baja desde San Miguel, pasa por la parte noroeste y noreste del asentamiento de El Porvenir; atraviesa Santo Domingo Ingenio, llena los canales de riego -anteriormente utilizados para el cultivo de caña de azúcar-, continúa su trayectoria por los otros pueblos y desemboca en el sistema lagunar Huave, lo que propicia condiciones ambientales adecuadas para la pesca (ver Mapa 2).

Los recursos forestales también son importantes, ya que la explotación tanto de maderas finas como de maderas corrientes tropicales les ha permitido salir adelante en los momentos de crisis productiva. Por sus diferentes usos (combustible, construcción y elaboración de muebles), la madera ha estado amenazada por la tala clandestina y por la explotación por parte de acaparadores, sin embargo, fue precisamente en ese ámbito en el que los porvenireños establecieron los primeros mecanismos organizativos de defensa de sus recursos colectivos.

El ejido cuenta con 1.533 ha de temporal con $75 \%$ cultivable y 1.379 ha de agostadero con $20 \%$ laborable (DOF, 21/10/1940). El Programa de Certificación de Derechos Ejidales y Titulación de Solares Urbanos (en adelante PROCEDE) ${ }^{5}$ en 2006 certificó $2.787-61$ ha parceladas, $124-38$ ha del asentamiento (incluye superficie para asegurar su crecimiento) y 5-17 ha de uso común ${ }^{6}$. Sin embargo, aún continúa en trámite la regularización de una superficie excedente que tienen en posesión al norte y al poniente del ejido, cuya extensión es de alrededor de 1.000 ha, según los propios ejidatarios (Cfr. López, 2010).

Las cifras oficiales reconocen la existencia de 171 ejidatarios y 19 posesionarios. La extensión de las superficies que detentan varían desde una y hasta 133 ha de diversas calidades, repartidas hasta en ocho parcelas, resaltando el hecho de que ningún posesionario tiene más de 40 ha $^{7}$. La mayoría de los pobladores de El Porvenir son productores rurales dedicados tanto a la agricultura como a la ganadería, insertos en el mercado local y regional. Las actividades económicas complementarias son la recolección, la explotación forestal y la caza ${ }^{8}$. Otro sector de la población se emplea en actividades de comercio, transportes o servicios, mientras que una minoría trabaja en el área de la construcción.

Entonces, el ingreso de las familias se adquiere por distintos medios: el trabajo en el área de servicios en las ciudades cercanas, oficios temporales, producción de cultivos tradicionales para el autoconsumo, cultivos comerciales a pequeña escala, remesas de los migrantes en EUA, "apoyos" por parte de los familiares que desarrollan actividades profesionales en otras partes de la república, así como diversos subsidios gubernamentales: "Programa de Apoyos Directos al Campo (PROCAMPO), Programa de Desarrollo Humano Oportunidades (OPORTUNIDADES), programas a nivel estatal, entre otros".

Las dinámicas migratorias en los últimos 40 años han incluido la salida tanto de individuos como de familias completas, inicialmente a las ciudades petroleras de Salina Cruz y Coatzacoalcos (1970) y, posteriormente, a las grandes urbes del país - para trabajar y/o realizar estudios universitarios-(1980) y finalmente a los Estados Unidos de Norteamérica (1995-2002). Por lo tanto, la migración ha permitido el surgimiento de un "sector medio" integrado por profesionistas que viven fuera del ejido y ello ha incidido en la vida y en las actividades productivas de los porvenireños.

En la localidad es posible observar mayor presencia de mujeres, así como de hombres adultos, a su vez, muy pocos niños y jóvenes. Pero este panorama se transforma cada año durante el segundo fin de semana de febrero -fecha en la cual se realiza la fiesta agraria-, ya que llegan los migrantes y se percibe la continuidad de las relaciones con los que permanecen en el ejido. 
Efectivamente, aunque los porvenireños presentan mejores condiciones de vida respecto del municipio visto en conjunto, comparten muchos de los problemas que afectan a los habitantes del campo: deterioro ambiental, escasez de agua, pérdida de la autosuficiencia alimentaria, poca productividad, desempleo, emigración y pobreza. En este complejo panorama, consideramos que la organización ejidal y la ampliación de las funciones de la asamblea al ámbito civil y comunitario, por medio de la historia les ha permitido defender su territorio, distribuir las parcelas al interior, definir el acceso a los recursos colectivos, relacionarse con las instancias de gobierno, así como resolver problemas públicos, instalar y dar mantenimiento a los servicios mediante el tequio organizado en asamblea y forjar una comunalidad cuya historia se ha transmitido de generación en generación.

A continuación haré referencia a la historia de los porvenireños y a cómo la lucha por la tierra tuvo un significado importante, ya que no solo debieron asumir en conjunto la defensa de su territorio frente a la incursión de los vecinos, sino que implicó la negociación del conflicto interno y el establecimiento de una organización y una normatividad que, con el tiempo, asumió mayores funciones que las que marcaban los lineamientos oficiales con los que nació el ejido. Además señalaré los elementos que más adelante nos permitirán hacer una reflexión acerca de las características que comparten ejidos y comunidades -independientemente del tipo de población-, y aquellos aspectos en que consideramos que en El Porvenir se consolidó una comunidad ejidal.

\section{El proceso de formación del ejido (1934-1952)}

La historia de El Porvenir está ligada a la de la hacienda Ingenio Santo Domingo, de hecho, el ejido se formó con superficie perteneciente a esa finca9 ${ }^{9}$. Los solicitantes inicialmente fueron residentes de Paso Lagarto, ranchería periférica de la hacienda, y fueron expulsados por el patrón en 1925 por sumarse al agrarismo ${ }^{10}$. Algunas de las familias se instalaron en el casco de la hacienda y otras se refugiaron en Puerta Vieja, en terrenos pertenecientes a San Miguel Chimalapa y se caracterizaron por ser un grupo multiétnico de zoques, zapotecos y mestizos. $\mathrm{Si}$ bien las familias fueron acogidas en el territorio migueleño, continuaron como medieros en la finca, lo que los ubicaba en medio de los intereses de esos dos grupos, ya que por pactos sociales de respeto a la propiedad, las autoridades comunales de San Miguel Chimalapa mostraron su respaldo a los administradores del Ingenio Santo Domingo ${ }^{11}$.

Años después -1936- murió el patrón y la estructura de poder en la finca se resquebrajó, a partir de esto tomaron mayor fuerza los líderes del sindicato cañero, quienes no solo reprodujeron los tratos laborales de antaño, sino que hicieron más penosas las condiciones de empleo. A su vez, el proyecto agrario del presidente Lázaro Cárdenas (1934-1940) impulsó la dotación ejidal para los trabajadores de las haciendas, así que los antiguos peticionarios retomaron la lucha, ahora desde Puerta Vieja. Con el apoyo del maestro y promotor agrario Lázaro Blasí, realizaron la solicitud de tierras, además, bajo el consejo del líder agrario Froylán Cruz, sumaron a un sector de campesinos chimas para hacer más importante su demanda. El Comité de Puerta Vieja lo integraron David Toledo, Enrique Cabrera y Maximino Decena, la célula representativa de los solicitantes y los responsables de conseguir la dotación de tierras; $\mathrm{y}$ es a quienes los ejidatarios actuales recuerdan cada año en la fiesta agraria.

Los peticionarios de Puerta Vieja seguían viviendo en tierras prestadas por los migueleños y buscaban mejores tratos en la aparcería en los terrenos de la finca, ya que veían al ejido como algo incierto y necesitaban asegurar los medios de subsistencia. Por otra parte, la llegada de un nuevo administrador al Ingenio impulsó a los líderes sindicales a recurrir también a la solicitud agraria, fomentando el ejido como un complemento al trabajo en la industria azucarera. En 1937 se abrió el expediente de Santo Domingo Ingenio y sus anexos La Venta y La Blanca, con la ventaja de que todos ellos residían en las tierras que solicitaban y eran mayores numéricamente.

Así, desde la solicitud de dotación se definieron nuevas jerarquías: los peticionarios de Puerta Vieja buscaban su independencia tanto de los líderes y administradores como de los otros trabajadores de la finca, mientras que los peticionarios de Santo Domingo estaban mejor ubicados y en cierta forma podían subordinar a los otros solicitantes. Los dos grupos de peticionarios entraron en competencia por los recursos y la gente de Puerta Vieja decidió traspasar sus viviendas a la superficie de la finca, fundando así la localidad de El Porvenir, ello como una forma de presionar a las instancias 
gubernamentales para que agilizaran la resolución de su expediente y en un contexto marcado por la posibilidad de enfrentamientos violentos.

El dictamen del Gobernador sobre ambas solicitudes fue el 15 de febrero de 1940, mientras que las Resoluciones Presidenciales fueron firmadas el 28 de agosto de 1940. Santo Domingo Ingenio y anexas fue dotado con $10.286-70 \mathrm{ha}^{12}$ para 1.026 beneficiados (DOF, 18/10/1940), y El Porvenir con 2.912 ha para 174 beneficiados (DOF, 21/10/1940).

Los procesos de posesión provisional y definitiva de las tierras ejidales se desarrollaron de 1940 a 1947, con la marca de múltiples confrontaciones violentas entre los grupos de beneficiados. De acuerdo con la reglamentación oficial, los nuevos ejidatarios debían organizarse con las figuras del Comisariado Ejidal, Consejo de Vigilancia y Asamblea General, cuya legalidad era dada por la presencia de los agentes gubernamentales. Las autoridades del gobierno nombraron en 1940 al primer Comisariado Ejidal en El Porvenir, el que quedó integrado por el maestro Heriberto Sánchez, Higinio Hernández y Herón Toledo.

En esa época se definió Santo Domingo Ingenio como municipio libre, prácticamente con la superficie que antaño formaba la hacienda ${ }^{13}$, y los ejidatarios de El Porvenir tomaron la decisión de adscribirse al municipio de San Miguel Chimalapa. Esta anexión fue un mecanismo que les permitió mayor independencia, ya que por mucho tiempo estuvieron en oposición ante el autoritarismo de los líderes sindicales y ejidales de Santo Domingo que, en ese entonces, trasladaban la subordinación al ámbito administrativo. Además, muchas de las familias de El Porvenir tenían vínculos de parentesco con los migueleños y reconocían ampliamente su autoridad, facilitando la alianza política.

Una vez dotado el ejido y delineada una nueva organización interna, El Porvenir vivió un auge, como lo indican los censos, ya que de 1940 a 1950 el número de habitantes pasó de 181 a 368 (INEGI, 2013). Los ahora ejidatarios ya tenían sus parcelas de cultivo y si bien había diferencias en las capacidades productivas, ello no significaba un problema, además de que explotaban los recursos forestales y continuaron vinculados a los trabajos temporales de la agroindustria, sobre todo en la zafra.

En resumen, El Porvenir fue un asentamiento que surgió en la década de 1930 con los peticionarios de Puerta Vieja, quienes se vincularon al agrarismo cardenista y con ello al gobierno y al Estado. Como en buena parte de los núcleos agrarios formados en esa época, los ejidatarios de El Porvenir fueron apoyados por el maestro rural -líder letrado que luego se integró al ejido- y también por la Liga de Comunidades Agrarias y Sindicatos Campesinos del estado de Oaxaca (CNC); a su vez, ingresaron a las filas del partido de Estado, y siguieron las pautas organizativas que les marcó el gobierno.

Por lo tanto, podemos señalar que en ese entonces hubo una primera línea organizativa definida oficialmente, con el funcionamiento de la asamblea, el Comisariado Ejidal y el Consejo de Vigilancia, que defendieron el territorio obtenido -frente a los ejidatarios vecinos-, lograron cierta independencia -al formar parte del municipio de San Miguel-y marcaron el fin de la subordinación vivida con anterioridad.

La historia posterior tuvo un hito fundamental por un conflicto interno, a partir de ello surgieron mecanismos que ampliaron las funciones de la asamblea y en los cuales consideramos que adoptaron ciertas formas comunales en la organización del ejido.

\section{Crisis interna y reestructuración organizativa}

El cierre temporal del Ingenio en 1952, la consecuente baja en el mercado de la leña, y el aumento en el robo de ganado, desembocaron en una crisis interna sin precedentes. El recuerdo de los acontecimientos se maneja todavía con mucha discreción y forma parte de los relatos de la historia íntima de los ejidatarios.

Sucedió que uno de los ejidatarios -líder pionero- había sufrido pérdidas importantes en su hato ganadero, e influido por los chismes -y sin mayores averiguaciones-decidió hacer justicia por su propia mano y mató a uno de sus compañeros -quien realmente no había sido responsable del robo del ganado-. El asesinato dividió a la población y la violencia escaló a tal grado que familias enteras se exterminaron entre sí y otras tantas abandonaron el ejido (López, 2010).

Cabe mencionar que en esa época había mayor presión sobre los recursos sobrantes de la finca y estaba latente la violencia en la zona, pues se consolidaron los ejidos con procesos jurídicos muy importantes y se redujo al mínimo la propiedad privada del Ingenio ${ }^{14}$. El restablecimiento de las actividades agropecuarias y el repoblamiento de El Porvenir tuvieron relación 
justamente con los procesos de ampliación de los ejidos vecinos, ya que había posibilidades de que los solicitantes tanto de La Venta como de Santo Domingo se apropiaran de sus tierras.

Además, de 1950 a 1960 se extendió el trabajo asalariado en el Istmo por el crecimiento de la infraestructura carretera ${ }^{15}$, y el establecimiento del Distrito de Riego \#19, por lo cual la redefinición del ejido exigía acciones prontas y concretas. En efecto, rápidamente se integraron nuevos miembros al ejido: en 1954 había 31 ejidatarios que estaban incluidos en el censo de la dotación, y ya trabajaban la tierra otros 29 individuos procedentes de Santo Domingo y de diversas localidades de San Miguel (López, 2010).

Con la entrada de nuevas familias, los porvenireños comenzaron a marcar otros lineamientos para la convivencia, reforzados a su vez por un elemento simbólico de sustento en los nuevos comienzos: la construcción de la iglesia católica dedicada a la Virgen de Guadalupe, promovida por los zapotecos de Santo Domingo. Asimismo, con las nuevas alianzas ingresaron familias zoques, quienes probablemente también influyeron en la definición de las características organizativas actuales.

En esta reconfiguración observamos el desarrollo de diversos elementos que, salvo la posesión de un espacio territorial y la transmisión de una historia común, son considerados propios de las comunidades indígenas: un sistema de procuración de justicia, el consenso en asamblea para la toma de decisiones, el servicio gratuito en el ejercicio de los cargos, el trabajo colectivo en obras de bien común y la expresión festiva con sus ritos y ceremonias (Cfr. Vargas, 2010). Se trata de ingredientes de la comunalidad donde descuellan características y prácticas inherentes a los sistemas de cargos tradicionales.

En adelante, la organización ejidal se fue modificando y adaptando de acuerdo con los vaivenes de la convivencia interna y las políticas públicas. En el acceso a los créditos para la producción y de recursos para el desarrollo de la infraestructura a partir de la década de 1960 se fortalecieron las redes de cooperación entre las familias y la capacidad de administración de los servicios públicos, mientras que una década después las incursiones de los vecinos para explotar los agostaderos les impulsaron a organizar comisiones de vigilancia para la defensa de los recursos colectivos.

Las inversiones en el campo istmeño -en especial en los ejidos temporaleros- y la organización del trabajo en la época del presidente Luis Echeverría (1970-1976) se dio a partir de la explotación agrícola colectiva de maíz y ajonjolí, en lo que nuevamente la organización interna tuvo una papel importante, pues ello implicó la compactación de las parcelas y definió en gran medida la actual distribución y extensión de los terrenos de los ejidatarios.

La población aumentó paulatinamente de 498 habitantes en 1970 hasta alcanzar su mayor cifra -809 habitantes- en 1990 (INEGI, 2013). El retiro de las inversiones gubernamentales en la década de 1980 dio la pauta para un mayor impulso a las actividades forestales, a lo que se sumó la siembra de amplias superficies de mariguana, ello produjo una bonanza en las economías de los ejidatarios. En esos años fue posible que muchos enviasen a sus hijos a estudiar en las universidades del Distrito Federal. Pero la abundancia duró poco tiempo por la presencia del Ejército, que se quedó en el lugar varios meses y destruyó los sembradíos. Así que los porvenireños vivieron la segunda crisis más importante de su historia. Según nos cuentan los ejidatarios, su misma organización les permitió hacer frente a las presiones, evitar ser encarcelados y concluir favorablemente esa etapa de la vida del ejido.

Así como en los años 50 la nueva convivencia fue acompañada por la presencia de la Iglesia católica, en la crisis de los 90 lo estuvo por la entrada de la Iglesia protestante, ganando mayores espacios no solo en El Porvenir sino en las Chimalapas en conjunto.

Sin embargo, la población sintió los efectos de la falta de inversiones y durante los años 90 parte de la población del ejido se sumó a la emigración: en 1990, como ya se dijo, había 809 habitantes; para 1995 la cifra bajó a 780; 688 para el año 2000; en 2005 se registró a 625; y en el 2010 aumentó ligeramente a 668 habitantes (INEGI, 2013 y 2010).

La gente que se ha quedado en El Porvenir ha procurado estabilidad interna y durante mucho tiempo se negaron a participar del pluripartidismo, porque según su opinión: "no nos gusta la política, pues solo nos divide". Los ejidatarios siguen pensando el Partido Revolucionario Institucional (PRI), aunque a nivel del municipio hace aproximadamente dos décadas que surgieron simpatías hacia otros partidos políticos.

Hemos descrito a grandes rasgos cómo la organización ejidal resultó exitosa para enfrentar las dos crisis que se vivieron en el ejido, pero esto no hubiera sido posible si no se hubieran basado en 
una serie de reglas organizativas que han surgido de la asamblea general, como lo veremos más adelante. Aquí hay que decir que los ejidatarios de El Porvenir se unieron para proteger sus recursos forestales y construir el templo católico (1950); para administrar las inversiones gubernamentales en el área productiva (1960 a 1980); y para manejar las inversiones en servicios públicos e infraestructura social (de 1990 a la fecha).

Por otra parte, si bien se conserva la estructura típica de la organización ejidal -asamblea general, Comisariado Ejidal y Consejo de Vigilancia-, estos puestos de representación están inmersos en un sistema de cargos y no se limitan a las tareas formalmente asignadas, sino también intervienen en la gobernabilidad del colectivo.

\section{La comunidad ejidal}

En la década de 1970 la asamblea ya había demostrado ser un espacio para la conciliación de los conflictos internos y eje organizativo de las actividades para el bien común. En adelante, la asamblea adquirió funciones de gobernabilidad de gran importancia en la vida interna.

De Teresa (2000: 43) afirma que en los años noventa las formas generalizadas de la asamblea y el tequio en los pueblos de los Chimalapas más que una figura de tradición indígena local constituía un recurso organizativo básico del que disponía la población de la zona -indígena o no- para regular la vida colectiva. Y efectivamente es lo que observamos en El Porvenir en el consenso que se da en la asamblea para la toma de decisiones, fenómeno que se explica por el contexto regional y por la propia historia del ejido.

Para los porvenireños, la asamblea es el espacio donde se discuten los asuntos públicos internos: la agenda de trabajo para el mantenimiento de los servicios, la asignación y/o venta de las parcelas, la elección de autoridades, la presentación de los programas gubernamentales y el destino de los recursos relacionados con la fiesta agraria. Además, ha sido un espacio para conciliar los conflictos internos e impartir justicia.

Según el padrón general interno de 2008, la asamblea reconoce a 213 individuos con derechos y obligaciones establecidos por la costumbre. Entre los cuales destacan: obtener un lote para vivir, opinar acerca de los asuntos públicos, tener la posibilidad de elegir y ser elegido para desempeñar algún cargo, disfrutar de los terrenos de uso común -en proceso de regularización-, e integrarse a los programas gubernamentales.

La asamblea ejidal se reúne cada mes, aunque para los asuntos de carácter agrario lo hacen dos veces al año. Como ya mencionamos, la asamblea amplió e integró nuevas tareas a sus funciones originales, marcando las pautas de participación política del colectivo mediante un sistema de cargos de tipo escalafonario. Este es un sistema jerárquico en el que se va ascendiendo de acuerdo con el desempeño de tareas de menor a mayor responsabilidad.

Los criterios básicos para definir el comienzo de la participación de los individuos en las actividades políticas del colectivo son el género y la edad. $\mathrm{La}$ iniciación de los jóvenes en la vida cívica se hace en los puestos auxiliares de los comités de la iglesia o del kiosco -en los que las mujeres son las titulares-; y a partir de que los jóvenes contraen matrimonio, están obligados a participar como suplentes en los comités de la escuela, del agua o la fiesta y más adelante adquieren la titularidad en los mismos. Posteriormente pueden ser miembros del Consejo de Vigilancia y/o de la agencia municipal, y después de haber transitado todos estos cargos es posible que formen parte del Comisariado Ejidal.

A pesar de la estructura piramidal de esta organización, existe cierta flexibilidad para integrar a los individuos con las habilidades necesarias para el "buen desempeño" de los cargos, por ejemplo mayor escolaridad o habilidad en el manejo de la máquina de escribir. Es importante resaltar que todo el trabajo realizado es gratuito, incluso en el caso del agente municipal, quien normalmente percibiría un ingreso por parte de la cabecera municipal, sin embargo, no aceptan esta remuneración como una forma de evitar adquirir compromisos.

El trabajo colectivo ha facilitado la instalación de los servicios (agua, luz y otros) y la construcción de los edificios públicos que funcionan en el lugar (la casa ejidal, las oficinas de la agencia municipal, entre otros), al igual que el mantenimiento que se les da continuamente, todo ello mediante el tequio organizado en la asamblea.

Las asambleas efectivamente son espacios participativos a los que asisten gran parte de los ejidatarios, en su mayoría hombres. Y si bien los varones son quienes tienen voz y voto, el ejidatario no es un sujeto individual, es representante de un sujeto colectivo -la familia-, por lo que debemos pensar a la asamblea como una instancia donde 
está representado un grupo amplio de la población. Además, de acuerdo con la temática a tratar, se da una participación ampliada, por ejemplo en la organización de la fiesta agraria, en ella confluyen múltiples familias.

Igual que las ligas de parentesco unen a los ejidatarios, la asamblea constituye un espacio que genera sentimientos de pertenencia a un colectivo, encontrando su máxima expresión en la fiesta agraria. Esta celebración es la más importante del ejido, ahí se recuerda el proceso agrario, los líderes y sus luchas para conseguir la dotación de tierras, y si bien es un evento laico, guarda similitud con la organización zapoteca de las mayordomías religiosas -al estilo istmeño- (cfr. Münch, 2004: 61-74). En el ciclo ceremonial anual, la fiesta agraria es la más importante y asisten amigos y familiares de la región, del estado de Veracruz, de otros estados de la República e incluso los migrantes. La fiesta agraria incluye tanto la instalación de la feria, bailes, jaripeos, carreras de caballos, como la realización de misas y podemos indicar que se da cierta sacralización a la historia de la lucha por la tierra.

\section{Conclusiones}

El caso del ejido El Porvenir es el de una población que cuenta con recursos bióticos importantes y en su organización política, social y económica, en apariencia ha mantenido las formas organizativas surgidas de las políticas gubernamentales, pero lo ha logrado gracias a la formulación de una comunidad ejidal que le da sentido a la vida en colectivo.

La organización ejidal actual ha mantenido la unidad de un espacio territorial, por cierto mucho mayor al otorgado por la Resolución Presidencial de 1940. Un aspecto fundamental que les ayudó a desligarse de los trabajadores de Ingenio Santo Domingo fueron los vínculos con San Miguel: primero (1936) al establecer un asentamiento provisional en su territorio y luego (circa 1944) se adscribieron al municipio, aunque mantuvieron la organización ejidal como el eje de la vida en colectivo. Esta adscripción fue determinante para que los ejidatarios forjaran sus propios mecanismos en la toma de decisiones y para el desarrollo de los elementos de la comunidad ejidal.

El primer eje organizativo fue precisamente la defensa de su territorio y esa lucha se conmemora anualmente en la fiesta agraria, evento en el que se refuerza la transmisión de la historia común y da sentido a la proyección de un futuro para las nuevas generaciones. En las actividades desarrolladas con motivo de la fiesta agraria se da una expresión particular de ritos y ceremonias que giran en torno a la lucha por la tierra, pero que retoman elementos religiosos compartidos en la región, como lo es la organización de las mayordomías zapotecas.

La crisis interna de los años cincuenta y las presiones del contexto regional influyeron en el desarrollo de un sistema comunitario de procuración de justicia que ha implicado la negociación de los conflictos internos. "Hacer justicia por propia mano" fue una experiencia que tuvo como consecuencia una confrontación violenta entre hermanos, de tal forma que la administración de la justicia se presentó como una necesidad para convivir mejor en sociedad.

La vida del colectivo se organiza en la asamblea, cuya importancia radica en la capacidad que han tenido para resolver los problemas públicos, el mantenimiento de los servicios, su relación con instancias de gobierno y la distribución de las parcelas. La ampliación de las funciones de la asamblea al ámbito social, político, civil e incluso religioso, tiene relación con el consenso para la toma de decisiones, ya que gracias a este mecanismo han podido organizarse para proteger sus recursos y desarrollar trabajos colectivos en obras de bien común. Además, como ya mencionamos, desde jóvenes participan en un sistema escalafonario de puestos políticos y están obligados a prestar servicio gratuito en el ejercicio de los cargos.

Es necesario resaltar que en el contexto de la segunda Reforma Agraria (1992) se ha observado mayor difusión del arrendamiento de tierras debido a que con el PROCEDE se estableció la individualización de las unidades productivas y la consecuente posibilidad de rentar la tierra o venderla, además, al redefinir los derechos de acceso a la tierra se entrevé una posible redistribución de los papeles y los poderes, sin embargo, como hemos visto a grandes líneas, en el caso de El Porvenir, la asamblea ha mantenido su papel como eje organizativo en torno a los recursos colectivos, gracias a su capacidad de ir más allá de los lineamientos oficiales y hacer del ejido su propia comunidad. 


\section{Referencias Citadas}

Consejo Nacional de Evaluación de la Política Social, CONEVAL 2005 Documento electrónico disponible en [http://www. coneval.gob.mx/], consultado en mayo 2009.

De Teresa, Ana Paula, y Gilberto Hernández

2000 Los vaivenes de la Selva. El proceso de reconstitución del territorio zoque de los Chimalapas. Universidad Autónoma Metropolitana/ Consejo Nacional de Ciencia y Tecnología/ Secretaría de Medio Ambiente y Recursos Naturales, México.

Delgado Ramos, Gian Carlo

2003 "Recursos naturales, población y reordenamiento territorial: el caso del Plan Puebla Panamá", en Ecología política $\mathrm{N}^{\circ} 25$. Cuadernos de debate internacional, Icaria, Barcelona. Documento electrónico disponible en [http:// www.ecologiapolitica.info/ ep/25.pdf], consultado en julio 2010.

Escutia Solís, Edith Regina

2010 Tierra y poder en el ejido Misión de Chichimecas, San Luis de la Paz, Guanajuato 1920-2008. Tesis de licenciatura en Etnología, Escuela Nacional de Antropología e Historia, México.

Galindo, Carlos

2009 "Estrategias de planeación y actividades del World Wildlife Fund para la conservación en México", en Capital natural de México, vol. II: Estado de conservación y tendencias de cambio. Conabio, México. Documento electrónico disponible en [http://www.bio diversidad.gob.mx/pais/pdf/ CapNatMex/Vol\%20II/II10_Regiones\%20prioritarias\%20 y\%20planeacion\%20para\%20la\%20conservaci.pdf] consultado en julio de 2010.

García Barrios, Raúl, Beatriz de la Tejera Hernández y Kirsten Appendini (coords.)

2008 "La cooperación estratégica: una introducción al debate", en Instituciones y desarrollo. Ensayos sobre la complejidad del campo mexicano. Universidad Nacional Autónoma de México/ Centro Regional de Investigaciones Multidisciplinarias/ El Colegio de México/ Universidad Autónoma Chapingo, México.

Instituto Nacional de Estadística, Geografía e Informática, INEGI 2013 Archivo histórico de localidades. Documento electrónico disponible en [http://mapserver.inegi.org.mx/AHL/], consultado en junio de 2013.
Instituto Nacional de Estadística, Geografía e Informática, INEGI 2010 Censo General de Población y Vivienda. Documento electrónico disponible en [http://www.inegi.org.mx/sistemas/consulta_resultados/iter2010.aspx?c=27329\&s=est], consultado en mayo de 2013.

López Nazario, Melva y Jorge Antonio Acosta Calderón

2010 Cambio social y poder: la construcción del ejido El Porvenir, San Miguel Chimalapa, Oaxaca, 1936-2008. Tesis de licenciatura en Antropología social, Escuela Nacional de Antropología e Historia, México.

Münch Galindo, Guido

2004 "El sistema de cargos en las celebraciones del Istmo de Tehuantepec", en Palabras de luz, palabras floridas. Marcus Winter, et al., Universidad del Istmo, Oaxaca.

Padrón e Historial del Núcleos Agrarios, PHINA

2013 Documento electrónico disponible en [http://phina.ran. gob.mx/phina2/], consultado en junio de 2013.

Secretaría de Desarrollo Agrario, Territorial y Urbano, Dirección General de Comunicación Social, SEDATU 22 de abril de 2012, Comunicado $N^{\circ}$ 053, "La superficie de ejidos y comunidades de México, más grande que algunos países". Documento electrónico disponible en [http://www.sedatu. gob.mx/sraweb/noticias/noticias-2012/abril-2012/12166/], consultado en junio de 2013.

Vargas Vásquez, Liliana Vianey

2010 Las mujeres de Tlahuitoltepec Mixe Oaxaca frente a la impartición de la justicia local y el uso del derecho internacional (2000-2008), Tesis de licenciatura en Antropología Social, Escuela Nacional de Antropología e Historia, México.

\section{Periódicos}

Diario Oficial de la Federación, DOF 18/10/1940, Resolución en el expediente de dotación de ejidos al poblado Santo Domingo y anexos, Oaxaca.

Diario Oficial de la Federación, DOF 21/10/1940, Resolución en el expediente de dotación de ejidos al poblado Puerta Vieja, Oaxaca.

Diario Oficial de la Federación, DOF 16/03/1967, Resolución sobre el reconocimiento y titulación de bienes comunales del pueblo de San Miguel Chimalapa, municipio del mismo nombre, Oaxaca.

\section{Notas}

1 Tal como se autodefinen los porvenireños, pero veremos que ese mestizaje es de zapotecos y zoques, principalmente.

2 Santa María y San Miguel Chimalapa están ubicados en la parte oriente del estado de Oaxaca, en la región del Istmo de Tehuantepec. Forman parte del territorio denominado selva zoque y son los municipios más extensos de Oaxaca: entre ambos ocupan 594 mil hectáreas, aproximadamente $7 \%$ de la superficie del estado.

3 Los solicitantes del actual ejido El Porvenir habitaban anteriormente en una localidad cercana -ya desaparecida-, de nombre Puerta Vieja, la que efectivamente era la entrada al extenso territorio Chimalapa y marcaba los límites comunales respecto de la propiedad privada de la Hacienda Ingenio Santo Domingo.
4 En la región se denomina chimas a los habitantes de los municipios Chimalapas, en tanto que al interior se adscriben a su localidad de origen.

5 El objetivo del PROCEDE es regularizar los derechos de propiedad; localizar con certeza los linderos, parcelas, solares y terrenos de uso común, y reconocer la figura de avecindados que usufructúan tierras ejidales o habitan en la zona de asentamientos humanos. El término de su implementación gratuita fue en 2006 y participaron la Procuraduría Agraria (PA), el Instituto Nacional de Estadística, Geografía e Informática (INEGI), el Registro Agrario Nacional (RAN) y la Secretaría de la Reforma Agraria (SRA)

6 http://phina.ran.gob.mx/phina2/ 
7 Aproximadamente $11 \%$ tiene menos de 5 ha, el $49 \%$ tiene de 5 a 20 ha, el $21 \%$ de 20 a 40 ha, el $16 \%$ tiene de 40 a 70 ha, y $3 \%$ concentra más de 70 y hasta 135 ha.

8 Algunos de los frutos de la región son el nanche, la ciruela, el papáuce, la guanábana, el mango, el tamarindo, la papaya y la almendra, mientras que la caza se refiere principalmente a iguanas y armadillos.

9 A principios del siglo XX Ingenio Santo Domingo era una de las grandes haciendas en el istmo de Tehuantepec y fue un importante centro de atracción de mano de obra por el creciente cultivo de caña de azúcar. El reparto agrario afectó la propiedad de la finca y se formaron múltiples ejidos.

10 El patrón Gonzalo de Murga se enteró porque "un traidor le contó que las reuniones se hacían en la noche", les dio un plazo de ocho días para desalojar el poblado, y llegado el día, él y su escolta prendieron fuego a todas las casas.

11 Las autoridades de San Miguel presionaban a los solicitantes del ejido para que desistieran en su demanda, pues pedían la afectación de la hacienda Ingenio Santo Domingo.

12 Santo Domingo Ingenio y anexas recibió $1457-00-00$ ha de riego, 6.483-97-32 ha de temporal con 75\% laborable, 2.205-10-00 ha de agostadero con 20\% laborable, 83-60-00 ha de la zona urbanizada de Santo Domingo, La Blanca y La Venta, y 57-02-68 ha del río San Miguel Chimalapa.

13 Anteriormente la hacienda dependía administrativamente del municipio de Santiago Niltepec.

14 Las mejores tierras de la hacienda fueron afectadas en el periodo cardenista, sin embargo, el desmembramiento perduró hasta los años cincuenta, finalmente más de 34000 ha pasaron a la propiedad social por medio de las dotaciones, una división y varias ampliaciones, formando los ejidos Aguascalientes, El Porvenir, Santo Domingo Ingenio, La Venta y La Ventosa (López, 2010).

15 En 1951 entró en funcionamiento el tramo La VentosaArriaga de la carretera Panamericana. 
